\title{
PERFIL DE ESTUDANTES DO DISTRITO DE BREJO DO AMPARO- JANUÁRIA (MG) QUANTO AO CONSUMO E CONHECIMENTO SOBRE QUALIDADE DA ÁGUA: UMA ANÁLISE COM VISTAS À PROMOÇÃO DA SAÚDE NA ESCOLA
}

\author{
PROFILE OF STUDENTS OF BREJO DO AMPARO DISTRICT, JANUÁRIA \\ CITY, MINAS GERAIS STATE, ABOUT CONSUMPTION AND KNOWLEDGE \\ ON WATER QUALITY: AN ANALYSIS TOWARDS PROMOTION HEALTH \\ IN SCHOOL \\ Iza Manuella Aires1 Cotrim-Guimarães ${ }^{1}$, Luiz Carlos Ferreira ${ }^{2}$ e Anna Caroline de \\ Oliveira $^{3}$ \\ ${ }^{1}$ Instituto Federal do Norte de Minas Gerais - Campus Januária e Universidade Federal de Minas Gerais. \\ iza.cotrim@ifnmg.edu.br \\ ${ }^{2}$ Instituto Federal do Norte de Minas Gerais - Campus Januária, luiz.ferreira@ifnmg.edu.br \\ ${ }^{3}$ Programa de Iniciação Científica do Instituto Federal do Norte de Minas Gerais - IFNMG / Campus \\ Januária. annacarolineoliveira@ ymail.com
}

\section{RESUMO}

No mundo todo, a falta de saneamento e o consumo de água contaminada levam anualmente à morte de mais de 2,2 milhões de pessoas. A preservação da qualidade da água, portanto, exige atenção por parte das autoridades sanitárias e consumidores em geral. São fatores relacionados à contaminação da água: baixos índices de coleta e tratamento de esgotos, despejo inadequado de dejetos e animais, má condição de higiene da tubulação e dos tanques, dentre outros. Assim, a contaminação das águas naturais representa um dos principais riscos à saúde pública, pois está diretamente ligada a doenças acometidas pela população, especialmente aquelas não atendidas adequadamente por serviços de saneamento. Esse trabalho teve como objetivo geral identificar o perfil de estudantes do distrito de Brejo do Amparo-Januária (MG) quanto aos conhecimentos sobre qualidade e manuseio da água. Realizou-se a aplicação de questionário aos alunos das séries finais do Ensino Fundamental e do Ensino Médio de uma escola pública do distrito, escola exclusiva do distrito para estes níveis de ensino. Pode-se concluir que a maioria dos alunos não conhece os riscos do contato direto com a água contaminada, nem sobre as principais doenças de veiculação hídrica e formas de contaminação. Também foram identificadas práticas inadequadas de consumo e manejo da água pelas famílias dos alunos entrevistados. Ressalta-se que a pesquisa em questão teve como finalidade maior a proposição de um trabalho de educação em saúde para a escola pesquisada, no sentido de empoderar a população em relação ao trato com a saúde individual e coletiva.

Palavras-chave: Qualidade da água; Educação em saúde, Saúde na escola.

\begin{abstract}
Worldwide, the lack of sanitation and consumption of contaminated water have caused the death of over 2.2 million people per year. The preservation of water quality therefore requires attention from health authorities and consumers in general. Factors
\end{abstract}


related to water contamination: low rates of collection and treatment of sewage, inadequate disposal of waste and animals, bad hygiene of pipe and tanks, among others. Thus, contamination of natural waters is a major risk to public health because it is directly linked to diseases in the population, especially those not served by sanitation services. This work aimed to identify the profile of students from Brejo do Amparo District-Januária City (MG) and their knowledge on quality and handling of water. There was the application of a questionnaire to students of final grades of elementary school and the high school of the a public school of the district, exclusive school in the District to these levels of education. It can be concluded that most students don't know the risks of direct contact with contaminated water or about the main waterborne diseases and forms of contamination. Also inadequate consumption practices and water management by the families of the students interviewed were identified. It is important to emphasize that the research had as main objective to propose a health education work for the school researched in order to empower the population to the individual and collective health.

Key Words: Quality of water; Health Education, Health at School.

\section{INTRODUÇÃO}

No mundo todo, estima-se que as doenças transmitidas pela água sejam responsáveis por mais de dois milhões de mortes ao ano, principalmente entre crianças menores de cinco anos (CASE; FUNKE e TORTORA, 2012), devido, principalmente, à falta de saneamento e o consumo de água contaminada, especialmente nos países em desenvolvimento. A esse quadro acrescenta-se a falta de recursos para tratar a água e torná-la potável e própria para o consumo humano. Isso porque, ainda que a água seja um recurso ambiental indispensável à manutenção da vida, ela pode também veicular microrganismos nocivos à saúde humana (CRUZ; CRUZ e RESENDE, 2009).

A água para consumo humano é um dos importantes veículos de microrganismos causadores de enfermidades diarreicas de natureza infecciosa, o que torna primordial a avaliação de sua qualidade microbiológica e a sensibilização da população sobre os cuidados pertinentes à sua utilização para consumo. Uma forma de se realizar essa sensibilização seria através de ações educativas nas escolas de educação básica, ações estas de promoção da saúde a partir do ambiente escolar, sensibilizando os alunos, e por consequência, suas famílias, para a busca da compreensão de seus condicionantes e capacitando-os para a utilização de medidas práticas de promoção, proteção e recuperação da saúde ao seu alcance. Ressalta-se que todas essas ações são propostas pelos Parâmetros Curriculares Nacionais de Ciências (Naturais ou da Natureza - Biologia) e tema transversal Saúde. 
Dessa forma, o presente trabalho se propôs a realizar um estudo junto à população do distrito de Brejo do Amparo, do município de Januária (MG), por meio dos alunos da Educação Básica de uma escola pública do distrito, única escola que atende aos moradores da região nas séries finais do Ensino Fundamental e Ensino Médio.

O distrito em questão apresenta, segundo Oliveira (2015), a maior parte de suas residências em ruas não pavimentadas e possui também um grande índice de doenças de veiculação hídrica como a esquistossomose, por exemplo, apresentando também córregos que cortam o distrito onde já se verificou grande incidência de caramujos. Esses córregos são comumente utilizados pelos moradores para realizar suas atividades domésticas, inclusive para o consumo direto. Essas características motivaram os seguintes questionamentos, que nortearam o trabalho de pesquisa: qual o perfil da população do distrito de Brejo do Amparo em relação à utilização da água para consumo e lazer? Qual o nível de conhecimento dos alunos das séries finais do Ensino Fundamental e do Ensino Médio (vez que já estudaram diversos conteúdos relacionados ao tema em Ciências e outras disciplinas afins) sobre qualidade da água e veiculação hídrica de doenças? De que maneira as respostas a esses questionamentos poderiam direcionar uma ação educativa na própria escola e comunidade brejeira?

O presente trabalho teve como objetivo geral identificar o perfil da população do distrito de Brejo do Amparo - Januária (MG) quanto ao conhecimento sobre qualidade e manuseio da água. Como objetivos específicos, o trabalho se propôs a identificar o nível de conhecimento de alunos de uma escola pública do distrito sobre qualidade da água, doenças de veiculação hídrica e cuidados em relação à utilização da água disponível na região; traçar o perfil da comunidade em relação à utilização da água em suas diversas formas de disponibilização na região de Brejo do Amparo e propor à escola a adoção de medidas educativas sobre qualidade da água, de acordo com o resultado da pesquisa, a fim de sensibilizar a comunidade sobre o seu uso adequado.

\section{CONTAMINAÇÃO DA ÁGUA E VEICULAÇÃO DE DOENÇAS}

De acordo com Libânio, Chernicharo e Nascimento (2005), a contaminação das águas naturais representa um dos principais riscos à saúde pública, pois está diretamente ligada a doenças na população, especialmente aquelas não atendidas por serviços de saneamento. As doenças de origem alimentar, especialmente aquelas causadas por 
microrganismos patogênicos, persistem como um sério problema em todos os países, sendo a diarreia uma característica da maioria destas doenças, sendo que até $70 \%$ de todos os episódios de diarreia podem resultar da ingestão de alimentos e água contaminados.

D’Águila et al (2000) apontam que os principais agentes biológicos encontrados nas águas contaminadas são as bactérias patogênicas, os vírus e os parasitas, sendo as primeiras uma das principais causas de morte. Elas são as responsáveis pelos numerosos casos de enterites, diarreias infantis e doenças epidêmicas (como a febre tifoide), com resultados frequentemente letais. Além disso, algumas doenças como verminoses, esquistossomose e leptospirose são adquiridas pelo contato direto com a água contaminada.

Segundo informações da Agência Nacional de Águas (ANA, 2013), os baixos índices de coleta e tratamento de esgotos contribuem para problemas relacionados com a incidência de doenças de veiculação hídrica, comprometendo também a qualidade das águas superficiais, podendo inviabilizar o uso dos recursos hídricos. Somam-se a isso as inúmeras fontes de contaminação de água subterrânea potável, como o despejo de esgoto, lixões e fossas sépticas.

Já nos sistemas de distribuição de água potável, a água que deixa a estação de tratamento pode sofrer alterações em sua qualidade até chegar às torneiras. Para Fortuna et al., (2010), a contaminação pode se dar pela captação da água do sistema público, porém, na maioria das vezes está associada à má condição de higiene da tubulação e dos tanques (caixas d'águas) onde ocorre o acondicionamento da água que alimenta as torneiras. Esses reservatórios acabam permanecendo muito tempo sem manutenção, criando um ambiente favorável para a presença e sobrevivência de microrganismos nocivos aos seres humanos.

De acordo ainda com D’ Águila et al (2000), o melhor método de garantir que a água para o consumo esteja adequada é investir em formas de proteção, evitando-se contaminações de dejetos animais e humanos, os quais podem conter grande variedade de bactérias, vírus, protozoários e helmintos. Tais medidas podem ser incrementadas a partir de ações educativas junto à comunidade, em que a escola se apresenta na condição de espaço privilegiado para a educação para a saúde. 


\section{EMPODERAMENTO DA POPULAÇÃO POR MEIO DA PROMOÇÃO DA SAÚDE NA ESCOLA}

De acordo com o Ministério da Saúde (BRASIL/MINISTÉRIO DA SAÚDE, 2005), existem fatores determinantes para o estado de saúde ou de doença, e estes fatores estão diretamente ligados às condições vivenciadas pelo indivíduo como, por exemplo, o nível de desenvolvimento social e econômico, infraestrutura, grau de desigualdade de renda e outros. Esses determinantes contribuem significativamente para o surgimento de doenças ou também propiciam a saúde.

Sendo assim, reconhece-se atualmente a importância da busca de soluções coletivas e do acesso às concepções populares sobre as doenças para as estratégias de controle destas (AERTS et al, 2004; CLARO, TOMASSINI e ROSA, 2004). Nesse contexto, Buss (2009) ressalta que a promoção da saúde tem como finalidade assegurar a igualdade de oportunidades e capacitar as pessoas para que possam realizar completamente seu potencial de saúde. "Os indivíduos e as comunidades devem ter oportunidade de conhecer e controlar os fatores determinantes da sua saúde (p.30). A essa autonomia, Buss (2009) denomina empowerment (empoderamento).

Uma forma, portanto, de empoderar determinada população para assumir sua responsabilidade quanto à manutenção da saúde e melhoria da qualidade de vida seria através de ações de promoção da saúde. A escola, instituição em que todas as crianças brasileiras devem passar em determinado momento de sua vida, constitui-se no espaço ideal para essas ações educativas, inclusive como parte do programa curricular inerente à área de ciências naturais e saúde (COTRIM-GUIMARÃES, 2009), que dentre diversas unidades curriculares prevê a temática da água para consumo humano. Corroborando com essa afirmação, Cerqueira (2007) explica que a escola é um espaço privilegiado para a promoção da saúde, pois reúne crianças e adolescentes num período crítico de seu desenvolvimento, como também um ambiente de trabalho que reúne professores, outros profissionais e representantes da comunidade educativa.

Por tudo isso, é que a escola se constitui num espaço privilegiado de educação em saúde, proporcionando a intersetorialidade na educação para a saúde. Educação em Saúde é compreendida como qualquer combinação intencional de experiências de aprendizagem com objetivo de facilitar medidas comportamentais ou ações sobre os determinantes sociais da saúde a serem adotadas por pessoas, ou comunidades. (ASSIS 
et al, 2010, p.109). Nesse contexto, cabe à escola também estabelecer comunicação estreita com a comunidade onde está inserida.

Por tudo isso, a escola pode e deve se configurar num espaço de educação para a saúde, seja por meio do desenvolvimento de conteúdos afins em disciplinas do currículo escolar, seja através de parcerias com serviços de saúde.

\section{METODOLOGIA}

Este trabalho foi realizado com alunos das séries finais do Ensino Fundamental e alunos do Ensino Médio de uma escola pública, exclusiva do distrito de Brejo do Amparo (Januária - MG) para esses níveis de ensino. Dos alunos matriculados nesses níveis de ensino, 67,5\% foram entrevistados por meio de questionário com perguntas objetivas, que buscaram traçar o perfil quanto ao nível de conhecimento sobre o tema e quanto às características do consumo, tratamento e utilização da água para diversas situações.

Uma vez que a Escola pesquisada constitui a única escola do distrito que oferta as séries finais do Ensino Fundamental e Ensino Médio, atendendo os filhos das famílias locais; considerando o significativo número de alunos que respondeu ao questionário; considera-se que a amostra de alunos participantes da pesquisa foi representativa para o trabalho e possibilitou traçar as características do distrito em questão quanto ao objeto do estudo. Os dados foram analisados considerando a frequência das respostas ao questionário.

\section{RESULTADOS E DISCUSSÃO}

Inicialmente buscou-se traçar o perfil dos alunos entrevistados. Verificou-se que a idade mínima dos entrevistados foi de 12 anos, e que $52 \%$ dos alunos têm idade entre 12 e 14 anos. Dentre os alunos entrevistados apenas um relatou morar sozinho, e $52 \%$ destes moram com um número considerável de pessoas em casa, de 4 a 5 pessoas, além de 16\% morarem com 6 a 7 pessoas, resultado esse acima da média nacional, segundo o Censo 2010, que é de 3,34 moradores por residência (BRASIL, 2016).

Foi questionado aos alunos o que eles consideram que seja uma água de qualidade, cujas respostas encontram-se no Gráfico 01, a seguir: 
Gráfico1- Conceituação de água de qualidade, segundo os alunos entrevistados.

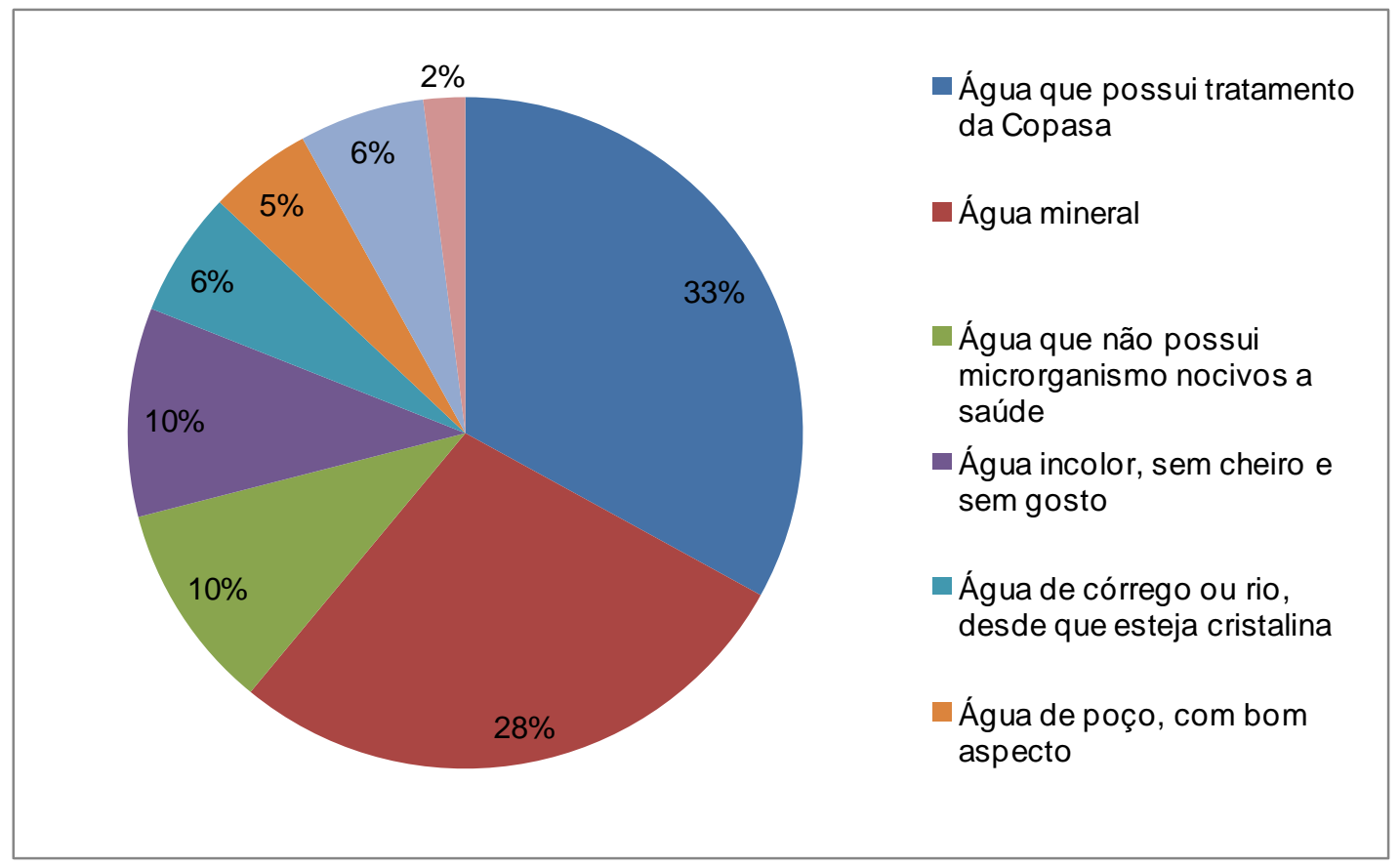

Fonte: Dados da pesquisa, 2015.

No que se refere à água da Copasa (Companhia de Saneamento de Minas Gerais), $65 \%$ responderam que não é necessário realizar outro tratamento em casa, que a água "da Copasa" é livre de microrganismos além de acreditarem que a água que chega às torneiras tem a mesma qualidade de quando sai da estação de tratamento. Apenas $32 \%$ acreditam que esta água pode conter microrganismos.

Uma parcela de $10 \%$ respondeu que a água de qualidade é a água insípida, inodora e incolor, pode indicar a existência de abordagens equivocadas, tanto na escola quanto fora dela, uma vez que somente essas três características não são suficientes para tornar uma água própria para o consumo. Apenas $10 \%$ dos entrevistados indicaram que o verdadeiro fator que torna a água imprópria para o ser humano: microrganismos nocivos.

Outro dado importante é que cerca de $17 \%$ responderam que água do córrego ou rio, desde que esteja cristalina, além de que a água de poço de bom aspecto e água da chuva também são águas próprias para o consumo. Isso é um relato preocupante na região, uma vez que a população costuma utilizar da água dos córregos do distrito de Brejo do Amparo para irrigação, lavar louças, roupas e até mesmo para o consumo direto, o que mostra que estes não possuem informação clara acerca dos riscos de contaminação que esta água pode causar. Da mesma forma, a utilização da água de poço 
é frequente (17\% de respostas) e destes, $5 \%$ consideram que esta é de qualidade, indicando que também não têm conhecimento sobre as doenças de veiculação hídrica através da água armazenada em poços.

Uma das questões respondidas pelos alunos foi a seguinte: Algumas doenças são transmitidas pela água contaminada. Essas doenças são adquiridas através de (...). Dos alunos entrevistados, $53 \%$ acreditam que a contaminação pela água se dá tanto pelo contato direto com a água contaminada quanto pela sua ingestão. 27\% não sabem que as doenças causadas por água contaminada se dão pelo contato com a água. Mais uma vez as respostas vêm ao encontro de situações recorrentes naquela comunidade, onde possuem o costume de ter contato com a água dos córregos que são utilizadas tanto para o lazer quanto para realização de tarefas domésticas, e que sendo esta água fonte de contaminação a população corre riscos de saúde. $15 \%$ não acreditam que a ingestão de água de má qualidade possa causar doenças.

Os alunos também tiveram a opção de indicar com que frequência "escutam falar" das seguintes doenças de veiculação hídrica: cólera; disenteria ou diarreia; hepatite A; febre tifoide ou paratifoide; esquistossomose; leptospirose e infecção intestinal. O objetivo dessa questão foi verificar se tais doenças, de alguma forma, fazem parte do cotidiano dos estudantes e suas famílias, por isso a pergunta "ouvir falar" ter sido utilizado no lugar de "conhecer", pois este último verbo poderia gerar o entendimento de que os alunos deveriam possuir saberes mais aprofundados sobre elas.

Segundo os alunos entrevistados, a doença mais apontada foi a disenteria ou diarreia, seguida pela infecção intestinal. Essas doenças podem ser contraídas através da ingestão da água contaminada e pelos resultados pode-se inferir que são comuns na região. Quanto à incidência dessas doenças, disenteria ou diarreia e infecção intestinal são as doenças que mais foram indicadas pelos alunos como tendo acometido os indivíduos do núcleo familiar. Ressalta-se que tais doenças ou quadros clínicos nem sempre são causadas pela água contaminada, mas há grande possibilidade de que seja a água o veículo do agente causador da doença. Já a esquistossomose, segundo apontamento dos alunos entrevistados, apresenta pelo menos 07 incidências entre os alunos ou seus familiares.

Quanto ao acondicionamento da água, os alunos foram questionados se possuem caixas d'água em suas residências, ao que $84 \%$ responderam que possuem, mas $14 \%$ não possuem. 
Os alunos foram questionados sobre acúmulo de água da chuva em sua residência, quintal ou rua, ao que 57\% responderam que há acúmulo de água. Os alunos foram também questionados se entram em contato com a água da chuva que se acumula, ao que $75 \%$ dos alunos dizem não entrar em contato com essa água que se acumula, mas $13 \%$ ainda têm contato com ela.

Outra questão investigada pelo trabalho se refere à utilização da água de córregos da região para o lazer da população. Através das respostas dos alunos pode-se observar que $66 \%$ não costumam tomar banho nos córregos. Cerca de $27 \%$ da população costuma tomar banho em alguns momentos.

Os alunos ainda responderam se possuem água tratada pela Copasa em casa, $59 \%$ dos alunos disseram que possuem água tratada pela Copasa, mas o dado mais importante é que $36 \%$ disseram que não têm, isso vem novamente atentar para um problema que acomete distritos e zonas rurais das cidades, onde muitas destas não são amparadas pelas companhias de abastecimento, deixando de consumir uma água de maior qualidade.

Destes $36 \%$ que não possuem água tratada, $63 \%$ retiram água de poço para o consumo, $12 \%$ retiram a água dos córregos ou rios e $25 \%$ retiram de outras fontes. Todas essas fontes não asseguram uma água de qualidade, muito pelo contrário, são águas que podem ser extremamente perigosas se consumidas, principalmente sem tratamento posterior. Dessas águas retiradas dos poços, córregos e outros, a maioria dos alunos diz que utiliza como principal tratamento a filtração (40\%), seguido pela utilização de hipoclorito (25\%), fervura da água (20\%) e outros meios (10\%). Ainda há aqueles que consomem esta água sem nenhum tipo de tratamento totalizando $5 \%$.

Uma outra pergunta foi direcionada à situação da água para beber. São $49 \%$ os alunos que disseram que retiram a água para beber principalmente do filtro, outra parcela, 19\%, diz que consome água mineral. A pesquisa aponta que 14\% dizem tomar água diretamente da torneira, um número bastante significativo. Além disso, $8 \%$ dos alunos indicaram que em algum momento consomem água de córregos para beber.

Quanto às questões de saneamento, 76\% dos alunos dizem ter vaso sanitário em casa, um dos avanços na questão sanitária do Brasil. Mas ainda têm pessoas que dizem ter banheiros com vala (buraco), são 5\% dos pesquisados. $80 \%$ dos alunos disseram que possuem fossa em casa, um grande vetor de doenças e poluidor do ambiente, que contamina o solo e lençóis freáticos e que ainda é utilizada como principal destino de dejetos. Esse grande número reflete mais uma vez a falta de 
informação sobre os males que a fossa causa e também mais uma vez como fator social, pois é cobrada tarifa de rede de esgoto juntamente com a conta de água e isso é um fator decisivo para que as pessoas ainda continuem a optar pela fossa. Nenhum dos alunos relatou que os dejetos do banheiro são despejados diretamente nos córregos.

\section{CONSIDERAÇÕES FINAIS}

Através desse trabalho pode-se concluir que uma parcela significativa dos alunos entrevistados não conhece os riscos do contato direto com a água contaminada, nem sobre as principais doenças de veiculação hídrica e formas de contaminação. Também foram identificadas práticas inadequadas de consumo e manejo da água pelas famílias dos alunos entrevistados. É importante registrar, entretanto, que a falta de conhecimento sobre manuseio e qualidade da água não é um fator isolado, visto que a região não apresenta uma totalidade na abrangência dos serviços básicos de saneamento, estrutura e condições adequadas para consumo direto e indireto da água em todas as residências.

Sendo assim, o trabalho da escola articulado a outros setores, como Unidade Básica de Saúde e às famílias de Brejo do Amparo possui grande relevância para melhorar esse quadro. Propõe-se à escola que sejam aplicadas medidas educativas, confecção de materiais informativos, ações e projetos voltados para o esclarecimento dos alunos quanto às doenças de veiculação hídrica, (forma de contaminação, prevenção, sintomas e tratamento) de forma a aliar a escola à realidade da comunidade do distrito, na tentativa de que os alunos, pais, educadores e profissionais da saúde participem como sujeitos colaboradores e promotores da saúde. Apresentando estas ações, a escola estará contribuindo como mediadora da educação para a saúde na escola e o desenvolvimento do aluno e toda comunidade escolar para que tenham a capacidade de se prevenir e ter a autonomia de tomar atitudes para que esta realidade seja modificada.

Por fim, é importante registrar que, para além da sensibilização dos alunos e familiares quanto ao manuseio adequado da água, os problemas apontados estão relacionados não apenas à falta de conhecimento ou hábitos saudáveis, mas também à falta de apoio e dotação de infraestrutura adequada pelas autoridades competentes. 
A escola pode dar uma contribuição nesse sentido, buscando despertar nos alunos e familiares um senso crítico quanto à problemática e sensibilizando-os quanto à possibilidade de mobilização junto à comunidade e ao poder público.

\section{REFERÊNCIAS}

AERTS et al. Convergência entre Vigilância da Saúde e Escola Cidadã. Cad. Saúde Pública, Rio de Janeiro, v. 20, n. 4, 2004. Disponível em < http://www.scielo.br/pdf/csp/v20n4/17.pdf>

AGÊNCIA NACIONAL DE ÁGUAS (ANA). Conjuntura dos recursos hídricos no Brasil. Brasília: ANA, 2013.

ASSIS et al. Educação em saúde - Proposta de utilização de um modelo no ensino de ciências. Revista Eletrônica do Mestrado Profissional em Ensino de Ciências da Saúde e do Ambiente (REMPEC).v.3, n 2, p.108-120, 2010.

BRASIL. Disponível em <http://www.brasil.gov.br/governo/2010/09/ibge-diz-quenumero-de-pessoas-que-moram-no-mesmo-domicilio-caiu >Acesso em 14 jan. 2016.

BRASIL/MINISTÉRIO DA SAÚDE. Curso de formação de facilitadores de educação permanente em saúde: unidade de aprendizagem - análise do contexto da gestão e das práticas de saúde. Rio de Janeiro: Ministério da Saúde/ Fiocruz, p. 33-34, 2005 .

BUSS, P.B. Uma introdução ao conceito de promoção da saúde. In: CZERESNIA, D. FREITAS, C.M. Promoção da Saúde: conceitos, reflexões, tendências. 2 ed. Ver. Amp. Rio de Janeiro: Fiocruz, 2009.

CASE, C. L; FUNKE, B. R.; TORTORA, G. J. Microbiologia. 10.ed. Porto Alegre: Artmed, 2012.

CERQUEIRA, M. T. A. Construção da Rede Latino Americana de Escolas Promotoras da Saúde. Em: Ministério da Saúde, Organização Pan-Americana de Saúde. Escolas promotoras de saúde: experiências no Brasil. Série Promoção da Saúde $n^{\circ} 6$. Brasília.2007.

CLARO, L. B. L; TOMASSINI, H. C. B; ROSA, M. L.G. Prevenção e controle do dengue: uma revisão de estudos sobre conhecimentos, crenças e práticas da população. Cadernos de Saúde Pública. Rio de Janeiro, v.20, n.6, p.1447-1457, 2004. Disponível em < http://www.scielo.br/scielo.php?script=sci_arttext\&pid=S0102311 X2004000600002\&lng=en\&nrm=iso\&tlng=en $>$

COTRIM-GUimarÃES, I. M. A. Programa de educação permanente e continuada da equipe de enfermagem da clínica médica do Hospital Universitário Clemente de Faria: análise e proposições. Dissertação de mestrado. Escola Nacional de Saúde Pública Sergio Arouca, Rio de Janeiro, s.n., 2009. 
CRUZ, J. B. F; CRUZ, A. M. S; RESENDE, A. Análise Microbiológica da Água Consumida em Estabelecimentos da Educação Infantil da Rede Pública do Gama, DF. Revista Saúde e Biologia, v.4, p. 21-23, 2009. Disponível em < http://revista.grupointegrado.br/revista/index.php/sabios2/article/view/138>

D'ÁGUILA et al. Avaliação da qualidade de água para abastecimento público do Município de Nova Iguaçu.Cadernos de Saúde Pública. Rio de Janeiro, v.16, n. 3, p. 791-798, 2000. Disponível em < http://www.scielo.br/scielo.php?pid=S0102311X2000000300027\&script=sci_abstract\&tlng=pt>

FORTUNA et.al. Análise microbiológica da água de cozinhas e/ou cantinas das instituições de ensino do município de Teixeira de Freitas (BA). Revista Baiana Saúde Pública Miolo. v.34, n.3, p.694-705, 2010. Disponível em < http://inseer.ibict.br/rbsp/index.php/rbsp/article/view/66>

LIBÂNIO, P. A. C.; CHERNICHARO, C. A. L.; NASCIMENTO, N. O. A dimensão da qualidade de água: Avaliação da relação entre indicadores sociais, de disponibilidade hídrica, de saneamento e de saúde pública. Eng. sanit. ambient. Brasília - DF. v.10, n. 3 - 219-22, 2005. Disponível em <

http://www.scielo.br/scielo.php?script=sci_arttext\&pid=S1413-41522005000300006>

OLIVEIRA, W. Junio. Análise e comparação da sensibilidade e especificidade entre diferentes métodos de diagnóstico para Shistosoma mansoni: Gradiente salino, Helmintex ${ }^{\circledR}$, centrífugo-sedimentação, Kato-Katz e teste rápido urina (POCCCA). Dissertação de mestrado - UFMG- Instituto de Ciências Biológicas Departamento de Parasitologia. Belo Horizonte, 2015. 